\title{
Video application to accommodate students' learning style for moral education in teacher education institutes
}

\author{
Mohd Razimi Bin Husin, Hishamuddin Bin Ahmad, Mahizer Bin Hamzah \\ Faculty of Human Development, Sultan Idris Education University, Malaysia
}

\begin{tabular}{l}
\hline \hline Article Info \\
\hline Article history: \\
Received Jan 9, 2019 \\
Revised Mar 2, 2019 \\
Accepted Mar 18, 2019 \\
\hline
\end{tabular}

Keywords:

Learning styles

Moral education

Multi-sensory instructional

packages

Technology

Video

\begin{abstract}
The purpose of this study is to explore the favored video applications in video use, compatible techniques and technology to accommodate the learning styles of moral education students in Teacher Education Institutes. This study is also to explore the contents of lesson suit to technology preferred by students in learning Moral Education. This is a case study in where data were collected through interviews. Six semester four students were chosen through purposive sampling from two Teacher Education Institutes in Malaysia. The constructs and internal validity were verified by experts while the external validity was verified through support from existing studies and theories. Data of the study were analyzed by using the Nvivo software to identify the features of favored video, compatible techniques and contents of lesson suit to technology that enhance the quality of teaching and learning of Moral Education to students. The Physiological Stimulus of Dunn and Dunn Learning Styles Model was used as guidance in the interviews because this model was the most suitable to be applied to students with Physiological Stimulus. The results of the analysis showed that short videos with suitable musics and short duration are the favored video for moral education students in teacher education institutes that enabled students to memorize the content knowledge. This research could be the learning guidelines on the use of videos and consequences activities of the shown videos that accommodate the learning styles of moral education students in Teacher Education Institutes which could be used by instructors in their professional practice in the lecture room.
\end{abstract}

Copyright $@ 2019$ Institute of Advanced Engineering and Science. All rights reserved.

\section{Corresponding Author:}

Mohd Razimi Husin,

Faculty of Human Development,

Sultan Idris Education University, 35900 Tanjung Malim, Perak, Malaysia.

Email: razimi@fpm.upsi.edu.my

\section{INTRODUCTION}

An indicator that distinguishes a student from another student is to see the way they understand the new information and the way they process the information. The educators' understanding of the distinguishes a student from another student would improve the quality of the teaching and learning process. According to Dunn and Dunn [22], each student has his or her own way of focusing, processing or storing new and complex information. During the learning process, students will try to focus when lecturers begin to teach, and they will try to process the information presented by the lecturer and then keep the information in their conscious mind. Therefore, Dunn and Dunn's Learning Style Physiology Stimulus was used as a guide in the interviews to obtain data on the study of information acceptance in the learning of Moral Education.

Previous studies have found that theater application of the Moral Education teaching styles used during lectures and tutorials do not conform to students' learning styles to meet the needs and interests of students. However, the findings showed that the use of video clips is in line with the students learning styles 
$[15,17]$. A set of personal effective features in receiving, type of video fonder by students and its preferred activities and processing information in learning through video applications has yet to be explored. Additionally, the concept of use, the essential and appropriate material in video applications also require deep exploration $[8,15]$.

Another study found that learning based on student learning styles helped students to receive information more effectively [1]. Previous studies have shown that there is a link between the learning styles and the use of the latest technology. According to Dunn, Dunn and Perrin [22], the use of technology is an element in physiological stimuli. Similarly, the selection of approaches and methods of delivery to students should be in accordance with the learning styles as the findings have shown students respond positively, receive information easily and get better performance especially when adapted to the latest technology $[4,5]$. Existing studies focus on the learning styles of pupils in schools and not students in institutions of higher education. Therefore, the findings of students' learning styles in schools are more readily available and guided than students' learning styles in institutions of higher education. While lecturers also need guidance to deal with trainee teachers for more effective lectures and tutorials which are in accordance with their learning styles. Lectures and tutorials that take into account the inclination of students' learning styles are in line with the appropriate activities for the trainee teachers through specific techniques that will have a high impact. As some students of higher education institutions are more likely to use video, effective video usage techniques will be explored through this study. High quality learning takes into account the teaching factor as the instructors are able to improve their students' achievement through quality teaching $[2,18]$. Hence, this study empirically explored video applications on how Moral Education students receive information to develop a model of video application based on students' learning styles for the education practitioners.

This paper present on the topic "Video Application to Accommodate Students' Learning Style for Moral Education in Teacher Education Institutes". This study was conducted to three objectives that was first, explore the favored video applications that enhance the quality of teaching and learning of Moral Education. Second objective was to evaluate the compatible techniques and technology in learning Moral Education, and third objective was to explore the contents of lesson and technology in learning Moral Education. This study used a case studies that involved interviews. The results of the analysis showed that short videos are the favored video for the students. Whereas the compatible techniques involve the way of lecturer instruction, the activities of Imitation and simulation, and conclude the story. This research could be the learning guidelines on the use of videos to instructors in their professional practice.

\section{RESEARCH METHOD}

This study used a qualitative approach of case studies that involved interviews whereby data were collected using interview protocols, audit trail notes, and video recorders. The students' learning analysis was carried out using Nvivo software that determined the findings of this study. Case studies require detailed investigations into individual or group practices, cultures or behaviors [24]. Case study on these students will show their real needs and lecturers can plan to meet those needs [26].

The participants of this study consisted of six students from two selected campuses in one of the zones of the Teacher Education Institutes. The selection of the research participants was based on purposive sampling that met the specific criteria specified. The specific criteria were based on research issues to be studied in depth to ensure the right choice of participants [20, 23, 24].

The study procedures are conducted according to a certain stage. There were five preliminary sequences implemented. The first stage, a preliminary study was conducted to identify the issues and problem statements of the study. Furthermore, literature review was conducted in depth on the concepts related to the objectives of the study. The second stage involves the application of Video Application to Accommodate Students' Learning Style for Moral Education in Teacher Education Institutes which was also based on the appropriate model. Saturated themes from the data collected should be found out. This is to avoid the bias conclusion by researcher. It can be biased from researchers conducting interviews. Usually bias occurs to survey items as happened in the study by Ahmad, Mokshein and Husin [6]. In the qualitative approach, bias can occur through the way interview conducted.

The selected model in this study was Dunn and Dunn's Learning Styles Model on Physiology Stimulus. Then the researcher started the third stage by conducting a pilot study to test reliability and form interview protocol to students from Teacher Education Institutes in Malaysia. Upon completion of the interview protocol, real field studies were conducted by conducting interviews. In the fourth stage, researchers made data analysis and process them through continuous comparisons using Nvivo software. Finally, the fifth stage, the researcher formulated, discussed the findings and wrote the research cover.

The system code is used to prevent repetitions on the data. There are two categories of code that is major codes and sub codes. Major codes are for general and broad information. While the sub code is for 
information that divides major codes into parts [20]. The coded category will be listed by summarizing it [20]. Then listed the codes alphabetically or according to the suitability of the research to use it again. Husin [14] uses a symbol code followed by the codes' description. For this study, researchers use the summary code based on the stimulus and the element of the learning style found in the Dunn and Dunn Models. Table 1 explains the examples of major codes, sub codes and the elements of sub codes.

Table 1. Major codes and sub codes

\begin{tabular}{|c|c|c|}
\hline $\begin{array}{c}\text { Major Code (Cases and } \\
\text { Stimulus) }\end{array}$ & Sub Code & $\begin{array}{c}\text { Elements of Sub } \\
\text { Code }\end{array}$ \\
\hline $\begin{array}{l}\text { Moral Education Students } \\
\text { (Major Code: MES) }\end{array}$ & Perception & $\begin{array}{r}\text { Short videos } \\
\text { Ads }\end{array}$ \\
\hline $\begin{array}{l}\text { Physiology (Major Code: } \\
\text { P) }\end{array}$ & $\begin{array}{c}\text { Feelings } \\
\text { Characteristics }\end{array}$ & Enjoyment \\
\hline & Imagery & $\begin{array}{r}\text { Interesting } \\
\text { storyline }\end{array}$ \\
\hline & & $\begin{array}{l}\text { Imagine herself } \\
\text { as the character }\end{array}$ \\
\hline Emotion (Major Code: E) & Perseverance & Short Period \\
\hline
\end{tabular}

\section{RESULTS AND ANALYSIS}

The use of video among students at the Teacher Education Institutes of Malaysia (TEIM) is a focus aspect of learning styles in this study. Some of the key points that were found in the study involving students who favored video applications in learning, compatible techniques and technology, and contents of lesson and technology.

\subsection{Favored videos}

Short videos with suitable musics and the short duration of the videos are the favored video for moral education students in teacher education institutes. The favored video could stimulate learning that made the students interested in the video they watched as the following transcript;

(MES: P/ Feeling/ Enjoyment): " The video, I mean enjoyed me is as if it were advertisements."

When Zira was asked about what she needed, she replied;

(MES: P/ Effective videos): "Therefore, effective video creation should take into account some important things."

Besides, the good videos should take into account the using both verbal and visual cues, good and simple storyline. Besides, the short videos must give a very meaningful, touching and a profound effect. According to Hani and Ain, the suitable music is a element that needs to be in the videos as in the following transcript;

(MES: P/ Feeling/ Music): "as an adult student, to me, I think the music is a element that needs to be in the videos .., the sound background does not need to be over likes the instrumental music, it's just as adequate as we hear something. But if it's a video. The video is a multimedia that speaks. I like music, so when it music is okay should be easy to understand the lessons". transcript;

When Ain was asked about the suitable music, she gave the music types as in the following

(MES: P/ Feeling/ Music types/ romance or ballads): "The music that is relevant to the video and the music needs to coincide with the title of that day. Music types, maybe romance, ballads".

So, the following types of music are recommended for the short videos likes romance, ballads or classical music for being peaceful and harmonious. Someone who likes to study with soft music in the background will easily get information when it comes to soft music during learning [3, 16]. Music timed at 60 beats-per-minute can help put people's minds into ease and relax. As well the nature soundtracks like waterfalls, rain or the sounds of the seashore also can help put people's minds into ease and relax. Instructors have to ensure that the music played to students in short videos is not "chill out", not roam too much, not distracting and should ultimately focus on content and doesn't distract the lesson. According to Arif, Daud and Basalamah [10], by optimizing the threshold and blob area values taken through a camera will result in the accuracy of the view. When using the camera, it is necessary to optimize threshold and blob area values to produce precision of view. 
The favored videos should take into account is the duration of the videos. According to Dunn and Dunn [21], learning ability within a certain period of time is one of the elements of perseverance in emotional stimulus as reported below;

(MES: E/ Perseverance/ Short Period): "Interestingly, it looks like a story, looks like a story. Take a look at one of these movies in 20 minutes, a short story. That's interesting if we do not see that before, we do not know what's going to happen after that. We just know what's going to happen."

When Hani was asked about the suitable duration, she replied;

(MES: E/ Perseverance/ Short Period): “... we cannot watch the video for one hour it can not .., maybe a video is short but easier to grab what message conveyed in the video."

\subsection{Compatible techniques and technology}

Key points of compatible techniques involve the way of lecturer instruction, the activities of Imitation and simulation, and conclude the story. All these involvements have particular tools to use in the lecturer room.

The instruction should convey before any activity in general. Lecturers should explain again what to do after activities or video show in order to please students learning need as Zira stated;

(MES: P/ Instruction/ Tools): "Instructions from the lecturer are very important because if we do not know what to do we will not do that. We need a clear explanation from lecturer. Okay, for example, we need to make a map of I-Think about the religious system. Another way that a lecturer will write in a laptop, then display it on the screen. ... but usually the lecturer's instructions are clear."

Moreover, according to Ain, tasks will be easier to understand if accompanied by directives from the lecturers. Another compatible technique after video shows is imitation. The imitation should come with several tools such as camcorder and social media such as Facebook as Zira stated;

(MES: P/ Activity/Imitation): "We used to do an activity; we did something like simulation. Re-acting what we understand about something. The simulation should be recorded. When it was recorded, the other will be uploaded on Facebook for all reference."

The last compatible technique is concluding the story. The video is a learning material tell the lessons as Zira stated;

(MES: P/ activity/ Conclude the story): "After watching a video, lecturer should ask what you get from the video, then instruct us to write what we got from the video example, the video about love. We have told the values. If the lecturer asks me, I will answer what I watched from the video. That means that video is not just broadcast but the video is a learning material that day."

According to Sharlin, she can write about her understanding. She suggest several activities that associate with video shown that is gallery walk and simulation about the story. There are tools for writing in classroom that works for students such as Character Trading Cards, Friendly Letter Maker, Identify the Main Idea, Make another story, posters and a table of contents $[12,13]$. Whereas tools for gallery tour that suitable for the students are questions texts, chart paper, white board, documents, texts and images. Gallery tour allows students to be actively engaged as they walk throughout the classroom. They work together in small groups to share ideas and respond to meaningful questions.

How to use gallery tour is hang or place the questions or prompts in various places around the classroom to create about five stations. Group students into teams of three to five students. Each group should start at a different station. Groups will read at their first station, what is posted, and one recorder should write the group's responses, thoughts, and comments on the chart paper or white board. The groups rotate to the next station after three to five minutes. Students will read and discuss the previous group's response and add points of their own. Repeat until all groups have visited each station before they return to their first station to read all that was added to their first response. Then instructors facilitated the class to discuss what was they learned and make final conclusions about what they have done and discussed. Use a Gallery Tour at any point in the lesson to engage students in conversation that is after watching a story to discuss ideas, themes, and characters.

A simulation is an imitation of the operation of a real-world process or system. The requirement tools in implementation simulations are many that is suit to activities. In the action or re-action, suitable tools are prop and tool use in the script to support the actions.

\subsection{Contents of lesson and technology}

Besides the story should be complete and interesting, students were fonder of watching short video that were dense with moral values as their learning contents. Based on the interviews, students preferred videos which could bring about better focus moral values as reportedly below; (MS: P/ Ad/ Focus moral values): "An example is an ad that gives teaching at all." 
When Priyanka was asked about the short video that were dense with moral values, she replied as in the following transcript;

(MES: P/Short video/Noble values): "The videos should be related to the noble values we learn."

Some of the lessons that need to be exposed to the people are respect others regardless of age or social standing, have sense of family, can adjust and compromise, empathetic to others' needs, understand that does every person has religion or faith, speak up when perceiving a wrongdoing, tell the truth, do not hurt anyone physically, psychologically and emotionally, do not take something that belongs to someone else and love for education [19].

Besides that, the short videos are full with the elements of Moral and value to appreciated by viewers especially moral education students. The elements are included in the syllabus of Moral Education Courses. Among the important themes in the Moral Education are values, ethics, moral thought flow, naturalists, emotional, intuitionist and rationalist. Whereas Types of Value consist of topic of absolute value, relative value, objective value, subjective value, intrinsic value and instrumental value. In the sub topic of Moral dimension, the contents are about moral reasoning, moral feelings and moral treatment. While in the the Moral Principles, the topics are autonomy, altruism and justice. In the Pure Value students will learn about the disclaimer of pure value practice and the strengthening pure values.

\section{CONCLUSION}

This paper present on the topic "Video Application to Accommodate Students' Learning Style for Moral Education in Teacher Education Institutes". This study was conducted to three objectives that covered the favored video, the compatible techniques and technology, and the contents of lesson and technology in learning Moral Education. The results of the analysis showed that short videos are the favored video for the students. The compatible techniques of this research could be the learning guidelines on the use of videos to instructors in their professional practice. Study by Kanagasabai [9], states that simulation results show that the Enriched Brain Storm Optimization (EBSO) algorithm is superior to other algorithms in reducing the real power loss. So, it is recommended that further research pertaining to the study focuses on the reduction of real power loss in video-making, man power during video-making. As well the content of the video friendly to audience and extremely effective to audience who watch it. It also recommended that further research pertaining to the study focuses on the reduction of power consumption, reduction of mobile data uses when watching it in a classroom using any gadgets app.

A studies conducted by Bhuyan, Hota and Panda [25], suggest a suitable model before conducting research on the effectiveness of the model. Finally, once the data is obtained, then the actual model is formed. Therefore, the future researcher's study on video suggested to refer to this study in formulating a modelrelated video-making before the model is validated through the findings of the study.

The findings of this study have revealed several favorable effects on the use of effective videos and quality related activities to maintain students' focus on lessons. Hence, instructors are encouraged to choose the appropriate videos and supporting activities that are very meaningful and profound effect of emotions in humans. In a nutshell, instead of instructors' creativity, the suitable activities to students learning styles should be stressed which could enhance students understanding on learning.

\section{ACKNOWLEDGEMENTS}

The authors would like to express their thanks to Universiti Pendidikan Sultan Idris (UPSI) for the sponsor of the Special University Research Grants (Research code: 2017-0275-107-01). Thanks to the management and administration of UPSI, the Research Management and Innovation Centre (RMIC) of UPSI who provided encouragement and commented for further improvement of this research and excel in the nation's education. Last but not least, thanks to everyone who involved directly or indirectly in this study.

\section{REFERENCES}

[1] Aziz, "Kepelbagaian Gaya Pembelajaran dan Kebimbangan Bahasa Guru Pelatih Major Bahasa Arab," in Ph.D. dissertation, Dept. Languages, UniSZA, Malaysia, 2016, pp. 230-239.

[2] A. Rogowsky, B. M. Calhoun and P. Tallal, "Matching Learning Style to Instructional Method: Effects on Comprehension," Journal of Educational Psychology, Vol. 107, pp. 64-78, 2014.

[3] E. Sulaiman, "Pengenalan pedagogi” In Kaedah Pengajaran," chap 5, pp. 73-95, 2004.

[4] G. Hardaker and A. A. Sabki, "An Insight into Islamic Pedagogy at the University of al-Qarawiyyin," Multicultural Education and Technology Journal, Vol. 6, pp. 106-110, 2012.

[5] G. Hwang, H. Y. Sung, C. M. Hung, and I. Huang, "A Learning Style Perspectiveto Investigate the Necessity of Developing Adaptive Learning Systems,” Educational Technology and Society, Vol. 16, pp. 188-197, 2013. 
[6] H. Ahmad, S. E. Mokshein, and M. R. Husin, "Detecting Item Bias in an Anatomy \& Physiology Test for Nursing Students using Item Response Theory," International Journal of Academic Research in Progressive Education and Development, Vol. 7, pp. 97-110, 2018.

[7] J. Laguzzi, S. Bernardi, A. M. Araujo, A. C. Ventura, and F. A. Vigliano, "Learning-styles of students of veterinary medicine in the National University of Rosario, Argentina," Revista Veterinaria, Vol. 24, pp. 151-156, 2013.

[8] K. Chorianopoulos, “A Taxonomy of Asynchronous Instructional Video Styles," International Review of Research in Open and Distributed Learning, Vol. 19, pp. 294-311, 2018.

[9] L. Kanagasabai, "Shrinkage of Real Power Loss by Enriched Brain Storm Optimization Algorithm," IAES International Journal of Artificial Intelligence (IJ-A1), Vol. 8, pp. 25-33, 2019.

[10] M. Arif, S. Daud and S. Basalamah, "Counting of People in the Extremely Dense Crowd," IAES International Journal of Artificial Intelligence (IJ-AI), Vol. 2, pp. 51-58, 2013.

[11] M. Foroutan, N. Nooreen, S. H. Gani and R. Baki, "The Relationship between Language Learning Autonomy Extent and Learning Styles in Malaysian Context," World Applied Sciences Journal, Vol. 24, pp.395-402, 2013.

[12] M. Kennedy and T. J. Dunn, "Improving the Use of Technology Enhanced Learning Environments in Higher Education in the UK: A Qualitative Visualization of Students' Views," Contemporary Educational Technology, Vol. 9, pp.76-89, 2018.

[13] M. N. Giannakos, L. Jaccheri and J. Krogstie, "Exploring the Relationship Between Video Lecture Usage Patterns and Students' Attitudes," British Journal of Educational Technology, Vol. 47, pp. 1259-1275, 2016.

[14] M. R. Husin, "Exploring the use of digital devices amomg pupils with learning disabilities," The International Journal of Multimedia \& Its Applications (IJMA), Vol. 9, pp. 75-86, 2017.

[15] M. R. Husin, H. Ahmad and M. Hamzah, "Making Short Video and Multi-Sensory Instructional Packages for Moral Education Courses in Teacher Education Institutes," Global Journal Of Advanced Engineering Technologies And Sciences, Vol. 5, pp. 9-18, 2018.

[16] M. R. Husin, H. Ahmad and M. Hamzah, "Video Application Model in Learning Styles of Moral Education Students in Teacher Educational Institution," International Journal of Engineering and Technology (UAE), Vol. 7, pp. 21-26, 2018.

[17] M. R. Husin, N. Ghazali and S. Haris, "Penggunaan Teknik Teater Terhadap Penerimaan Maklumat Pelajar Pendidikan Moral: Satu Kajian Kes," in Seminar Pendidikan dan Inovasi Kebangsaan Institut Pendidikan Guru Malaysia, 2017, pp. 13-20.

[18] M. W. Ngware, M. Oketch and M. Mutisya, "Does Teaching Style Explain Differences in Learner Achievement in Low and High Performing Schools in Kenya?," International Journal of Educational Development Vol. 41, pp. 4-13, 2014.

[19] Panduan umum struktur kursus PISMP ambilan Jun 2016 Institut Pendidikan Guru Malaysia, in Penerbit IPGM, Cyberjaya, 2015, pp 20-40.

[20] R. C. Bogdan and S. K. Biklen, "Qualitative Research in Education." in An Introduction to Theory and Methods, 1998, pp. 30-45.

[21] R. Dunn and K. Dunn, "The complete guide to the learning styles inservice system." in Identifying Participants' Learning Styles, 1999, pp. 30-45.

[22] R. Dunn, K. Dunn and J. Perrin, "Teaching young children through their individual learning styles: Practical approaches for grades K-2." In Designing Multisensory Instructional Packages to Respond to Individual Learning Styles, 1994, pp. 319-350.

[23] R. K. Yin, "Case study research: Design and Methods (Fourth Edition ed.)." in Case Studies as Qualitative Research, 1998, pp. 20-43.

[24] S. B. Merriam, "Qualitative research and case study applications in education." in Case Studies as Qualitative Research, 1998, pp. 26-43.

[25] S. K. Bhuyan, P. K. Hota and B. Panda, "Modeling and Simulation of Grid Connected Hybrid Energy System and its Fault Analysis," International Journal of Power Electronics and Drive System (IJPEDS), Vol. 9, pp. 775-783, 2018.

[26] Teaching students with autism, in A resource guide for schools, Victoria: British Columbia, 2000, pp 15-45. 